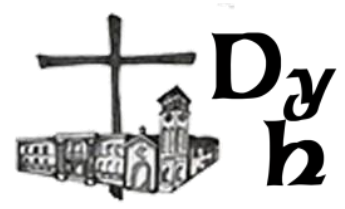

Una alternativa para vivir el embarazo felizmente y no como un problema

Entrevista a Juana Raimondi Joaquín Morosi - Martín Rossi Dios y el hombre, vol. 3, n. 2, e048, 2019 ISSN 2618-2858 - https://doi.org/10.24215/26182858e048 https://revistas.unlp.edu.ar/DyH/index Cátedra libre de pensamiento cristiano - UNLP Seminario Mayor San José La Plata, Buenos Aires, Argentina

\title{
UNA ALTERNATIVA \\ PARA VIVIR EL EMBARAZO FELIZMENTE Y NO COMO UN PROBLEMA Entrevista a Juana Raimondi
}

An alternative to live the pregnancy happily and not as a problem

An Interview with Juana Raimondi

\section{Joaquín Morosi | Martín Rossi}

joaquin.morosi@gmail.com | rossimartin21@gmail.com

Instituto Sudamericano para la Enseñanza de la Comunicación - Buenos Aires - Argentina I Seminario Mayor San José - La Plata - Argentina

\section{Resumen}

Desde hace algunos años funciona en nuestra Ciudad y alrededores Pies preciosos, una organización que se dedica al seguimiento y la ayuda de mujeres con embarazos vulnerables que consideraron abortar. Dios y el Hombre tuvo la oportunidad de entrevistar a una de las voluntarias para conocerlos mejor.

Palabras clave: Embarazo no deseable - Aborto - Mujeres vulnerables

\section{Abstract}

For some years, Precious Feet has been operating in our City and its surroundings, an organization dedicated to the monitoring and assistance of women with vulnerable pregnancies who considered abortion. Dios y el Hombre had the opportunity to interview one of the volunteers to get to know them better.

Key words: Undesirable pregnancy -Abortion - Vulnerable women 
Pasaron 428 días $^{1}$ desde que el Senado de la Nación desaprobó el Proyecto de Ley por la despenalización del aborto. Después de 16 horas de exposiciones, el debate arrojó como resultado 31 votos a favor y 38 en contra. Si bien la campaña electoral de este año puso en stand by la cuestión, Dios y el hombre pone en escena uno de los tantos disparadores que desgraciadamente no tuvieron un abordaje integral pese a la popularidad del debate en la sociedad argentina.

Acudimos a la palabra de Juana Raimondi, voluntaria de Pies Preciosos: una organización no gubernamental fundada en 2016 en la Ciudad de La Plata que surgió por iniciativa de un grupo de la Iglesia Arquidiocesana con el acompañamiento de Mons. Nicolás Baisi. La entidad se encarga del seguimiento general de los embarazos vulnerables abarcando distintas dimensiones y etapas, lo cual implica las instancias prenatales y los primeros meses de vida. El principal propósito que persigue Pies Preciosos es brindar contención a las madres embarazadas para evitar que aborten.

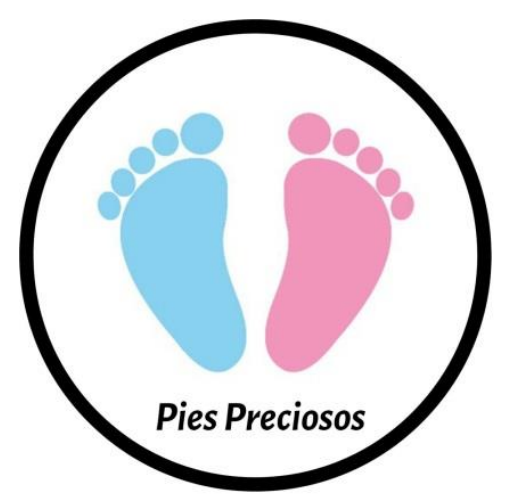

El logo con el cual se los reconoce en las redes sociales.

Acerca de lo ocurrido el año pasado, Juana nos decía: "a partir del debate yo pensé que se iba a tener más información y pasó todo lo contrario. Sólo se hablaba del aborto pero no se explicaba qué es. Creo que a partir de eso mucha más gente comenzó a considerar la opción de abortar. Hubo más casos, es cierto, pero con más desinformación. Entonces se acercaban mujeres sin saber qué tenían y sin saber qué iba a pasar si seguían con eso".

La gran mayoría de las madres con un embarazo riesgoso que se contactan con Pies Preciosos son de La Plata, Berisso, Ensenada, Magdalena y

${ }^{1} \mathrm{Al}$ momento de realizar la entrevista, 11 de Octubre de 2019. 
Punta Indio. Lo hacen habitualmente por medio de la web y de redes sociales. "A partir del primer contacto con las mujeres tenemos una entrevista personal a las que suelen ir acompañadas por su pareja o algún familiar cercano", nos contaba la entrevistada.

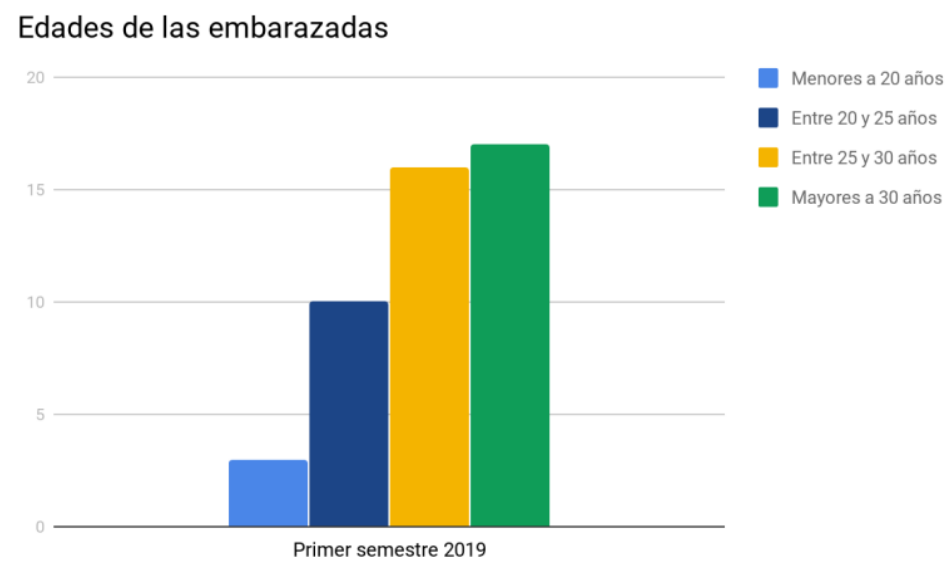

Las estadísticas del último año indican que la mayor parte de las mujeres asistidas tienen más de 30 años.

En todo el proceso se acompaña tanto a la madre como al recién nacido, asistiéndolos con un gran número de profesionales (obstetras, ginecólogos, psicólogos y especialistas en diagnósticos por imágenes) y otros voluntarios que aportan desde su lugar en otras actividades igual de importantes. Suman alrededor de 30 integrantes que alternan sus funciones y su nivel de participación en la causa. Si bien la idea es no molestar demasiado a las mamás, el equipo de seguimiento busca tener un contacto semanal con ellas para tener noticias de la evolución del embarazo y ayudarlas en lo que necesiten.

Existen momentos de mayor interés para involucrarse en la organización y tratar de dar una mano desde donde se pueda: "Después del debate en el Congreso mucha gente conocida se movilizó porque quería colaborar, entonces hicimos una reunión en la que se explicó de qué se trataba", en ese primer contacto con la organización los aspirantes a sumarse optaban por diferentes caminos de participación como el caso de una maestra que "empezó en la parte de seguimiento telefónico, pero no se sintió cómoda y prefirió dedicarse a un área en la cual tuviera contacto directo con las mujeres". 


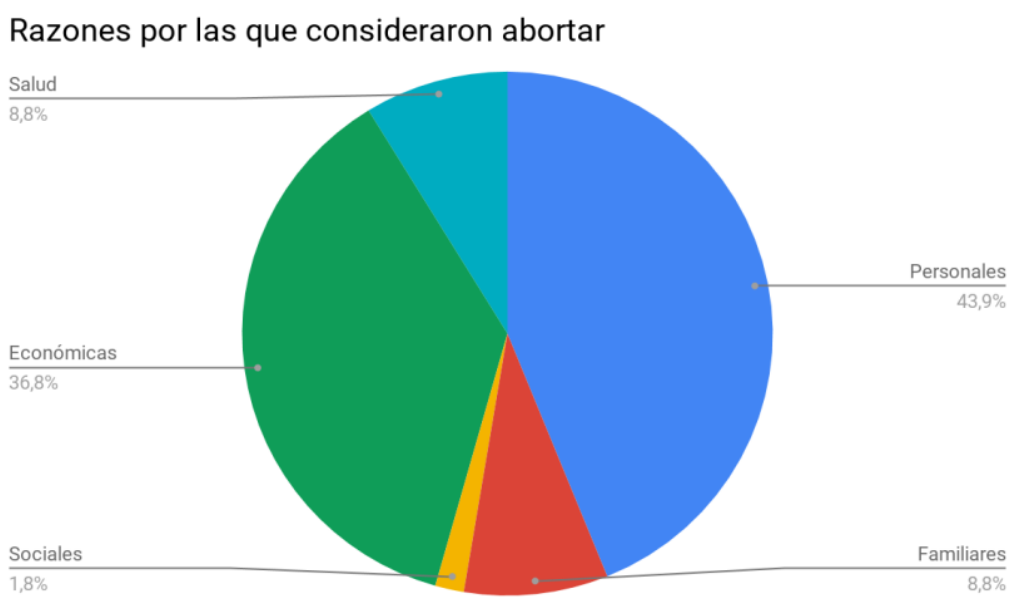

La mayor parte de las mujeres consideraron abortar por razones personales o económicas. Ninguna de ellas por una violación.

Al ser una organización surgida dentro de la Iglesia no es ajena a la evangelización de aquellas que buscan una contención más allá de la ayuda en el proceso de gestación y nacimiento: "cuando el trato con las mamás se hace fluido tenemos la oportunidad de acompañarlas en algunas situaciones conflictivas dentro del ámbito familiar, a través de un nexo con Cáritas parroquial para facilitar la ayuda material y también en los casos en que las mismas madres decidan bautizar al recién nacido".

En paralelo al trabajo de cada uno de los miembros fijos de Pies Preciosos la Iglesia platense aporta a la causa desde su oración comunitaria por aquellas mujeres que desde la necesidad recurren a esta ayuda y por aquellos que se encargan de recibirlas: "Cada vez que tenemos programada una entrevista se les avisa a las carmelitas para que recen por la misma; también hay un grupo de adoradores perpetuos que rezan por esas mamás. Este aporte es fundamental para nosotros, imprescindible para nuestro trabajo".

El acompañamiento de la organización se extiende hasta el primer año de vida fundamentalmente ya que "la idea es que las mamás puedan volar, uno las ayuda hasta cierto punto para que no queden atadas a nosotros, aunque siempre les queda un contacto por cualquier cosa". En la etapa cercana al nacimiento del bebé se cubren algunas necesidades materiales como la de un bolso que contiene pañales y todo lo que necesitan para el recién nacido: ropa, algodón, óleos, toallas, leche e incluso algún camisón para las mamás. Todo 
esto se sostiene económicamente gracias a los voluntarios y las donaciones de quienes se contactan con Pies Preciosos por medio de Facebook. Aquellos que estén interesados en colaborar con la organización lo pueden hacer a través de ese medio en cualquier momento del año. 